\title{
Hydration and Perceptual Responses Resulting from a Training Session Involving Female Rhythmic Gymnastics Athletes
}

\author{
Adriano Detoni Filho' ${ }^{1,2 *}$, Michele Guiramand ${ }^{1}$, Paulo Lague Sehl², Gabriela Tomedi Leites ${ }^{2}$ and Rafael \\ Reimann Baptista ${ }^{1}$ \\ ${ }^{1}$ School of Physical Education and Sports Sciences, Pontifical Catholic University of Rio Grande do Sul, Porto Alegre, Brazil \\ ${ }^{2}$ School of Physical Education, Federal University of Rio Grande do Sul, Porto Alegre, Brazil
}

Received: March 08, 2014; Accepted: April 04, 2014; Published: April 07, 2014

*Corresponding author: Adriano Detoni Filho, School of Physical Education and Sports Sciences, Pontifical Catholic University of Rio Grande do Sul - PUCRS, Tel: +55-51-3320 3683; E-mail: nano.detoni@gmail.com

\begin{abstract}
Young rhythmic gymnastics (RG) athletes engage in long training sessions that can lead to dehydration, especially on very hot days. Hydration status can affect the sporting performance and health maintenance of these young gymnasts. To evaluate the sweat volume, fluid balance and perceptual responses of young female RG athletes during a training session in the heat, fourteen female RG athletes $(11.3 \pm 2.6$ years) with a body fat percentage of $17.35 \pm 4.85 \%$ participated in this study. Body weight was measured and a urine sample collected for color analysis, both before and after the training session. The workout lasted $2.5 \mathrm{~h}$ in environmental conditions of between $29^{\circ} \mathrm{C}$ and $50 \%$ relative humidity (RH), and $30{ }^{\circ} \mathrm{C}$ and $59 \%$ RH. Water was made available for consumption ad libitum and sweat volume was calculated from the change in body weight, corrected for water intake. The rate of perceived exertion, thermal sensation, thermal comfort, and irritability were measured every 30 minutes using categorical scales. Sweat volume was $1146.6 \pm 412.6 \mathrm{~mL}$ and water consumption was $825.2 \pm 368.1 \mathrm{~mL}$. The negative fluid balance was between $1-2 \%$ in $50 \%$ and $1 \%$ in $42.8 \%$ of the athletes. Twelve athletes began the training session hypohydrated (urine color between 3 and 7), and 92.3\% were hypohydrated after training (urine color between 4 and 6). There was an increase in thermal sensation $(8 \pm 1)$ and discomfort $(3 \pm 1)$ over the course of the workout. The RG athletes were unable to adequately replace their fluid losses, despite water being available for drinking ad libitum, which may reflect on the perceptual responses to heat.
\end{abstract}

Keywords: Sweating; Hydration; Exercise in the heat; Gymnastics; Children

\section{Abbreviations}

RG: Rhythmic Gymnastics; BSA: Body Surface Area; RPE: Rate of Perceived Exertion; $\mathrm{VO}_{2 \max }$ : Aerobic Fitness

\section{Introduction}

Rhythmic gymnastics (RG), practiced mainly by girls, is a long duration sport with training sessions lasting around 3-4 hours daily. This may lead to dehydration, especially in hot weather conditions when sweating is more intense. The necessary skills that a gymnast requires are: strength, power, flexibility, agility, dexterity and stamina. The biotype of slenderness, desired in RG, causes many athletes to manipulate and restrict their intake of food and fluids to reduce body weight [1], which can compromise hydration status [2].

RG and other sports (judo, football, futsal) demand high aerobic fitness, strength, balance, coordination, perception and cognition $[3,4]$, skills that can be compromised when accompanied by a negative fluid deficit $>2 \%$ [5]. Young athletes from different sports (rhythmic gymnastics, tennis, football, futsal, judo), frequently begin training sessions and competitions hypohydrated and are unable to recover from one training session to the next [3,6-9], often using restricted fluid intake for the maintenance and loss of body weight $[3,9]$. A chronic state of hypohydration may decrease performance, motivation and physical effort during training and competitions [10].

The restriction of fluid intake combined with losses from sweating can be of concern both for performance and health. Physical training can affect the sweat responses in athletes [11]. No studies were found that evaluated the hydration and sweating status of RG athletes during a training session in the heat. The majority of studies evaluating hydration status, sweating and fluid intake in young athletes have focused on males [3-5] and a few studies have involved females, which involved protocols conducted in the laboratory [12-14].

Studies carried out in the field under normal training conditions are important in order to reflect specific training situations, such as heat stress and the availability of liquids. The aim of this research was to evaluate the hydration and sweating responses, and perceptual responses of young RG athletes during a training session conducted in the heat.

\section{Methods}

\section{Participants}

Fourteen female RG athletes, aged between 8-16 years, from the competition team of the Gymnastics Society of Porto Alegre (Sociedade de Ginástica Porto Alegre - SOGIPA) participated in 
the study. The physical characteristics of the athletes are shown in Table 1. The participants had no musculoskeletal injuries and none were taking medications that could affect the cardiovascular system and/or thermoregulation. All athletes had been training a minimum of four days a week for at least six months, with each training session lasting at least 2 hours 30 minutes. This study was approved by the Research Ethics Committee of the Pontifical Catholic University of Rio Grande do Sul, number CEP 11/05549, and those parties responsible for the athletes signed a consent form and the athletes signed a statement of consent for minors, agreeing to participate in the research. The study consisted of two sessions: one preliminary assessment and an evaluation training session.

\section{Preliminary assessment}

The first assessment was conducted three days prior to the training session and included an evaluation of maturational stage and anthropometry. The maturity level was assessed by a female researcher through observation of the breast region and pubic hair development, and classified using the Tanner criteria (1962). The height (Sanny portable stadiometer, model ES2040, 210cm, $0.1 \mathrm{~cm}$, Sao Paulo, Brazil) and body weight (G-TECH model 3 Glass control, Guangdong, China, $0.05 \mathrm{~kg}$ ) of athletes were measured whilst wearing a bathing costume only, and the body surface area (BSA) was calculated [15] using the following equation: (BSA = $0.20247 \mathrm{x}$ height $(\mathrm{m})^{0.725} \mathrm{x}$ weight $\left.(\mathrm{kg})^{0.425}\right)$.

Triceps and subscapular skinfold measurements were taken using Lange skinfold calipers (Cambridge, USA, $1 \mathrm{~mm}$ ) and the $\%$ fat was estimated by the Slaughter et al. [16] equation. The athletes were instructed to consume $\sim 375-500 \mathrm{~mL}$ of water, 30 minutes prior to the training session to try to balance the initial state of hydration.

\section{Training session}

The training session was conducted during an afternoon at the end of November 2011, a predominantly hot month in southern Brazil, and took place in a gymnasium (temperature $29.2 \pm 0.5^{\circ} \mathrm{C}$ and $59.3 \pm 2.8 \%$ relative humidity). It lasted a total of $2.5 \mathrm{~h}$ and consisted of $20 \mathrm{~min}$ of warm-up (stretching and light running with jumping), $1 \mathrm{~h} 50 \mathrm{~min}$ of technical and choreographed exercises, followed by $20 \mathrm{~min}$ of recovery (stretches).

Each athlete was asked to urinate and then body weight was measured. A sample of urine was collected for evaluation of the color; used as an indicator of the initial state of hydration [17].

During training, individual bottles containing water were available and positioned within easy access, for ingestion ad libitum. The bottles were weighed (Ohaus scale, model CS2000, New Jersey, USA, 1g) before and after the training session in order to calculate the total volume of liquid consumed. Body weight was again measured at the end of the training session to determine the hydration status of the athletes. The sweat volume $(\mathrm{mL})$ was estimated by the difference between pre- and posttraining body weight, corrected for the volume of water ingested during exercise. The sweat volume was divided by $\mathrm{kg}$ and time $\left(\mathrm{mLkg}^{-1} \mathrm{~h}^{-1}\right)$ to express the sweat rate.

The following perceptual variables were evaluated every 30 minutes: rate of perceived exertion (RPE) [18], thermal sensation, thermal comfort [19] and irritability [20]. The categorical scale for thermal sensation consisted of nine points ranging from very cold (1) to very hot (9); thermal comfort scale consisted of six points ranging from very comfortable (1) to very uncomfortable (6); and the irritability scale with five points ranging from nothing noticeable (1) to strong intensity (5).

Table 1: Physical characteristics of the athletes.

\begin{tabular}{|c|c|c|c|c|c|c|}
\hline ID & Maturational stage & $\begin{array}{l}\text { Age } \\
\text { (yrs) }\end{array}$ & $\begin{array}{c}\text { Weight } \\
\text { (kg) }\end{array}$ & $\begin{array}{l}\text { Height } \\
\text { (cm) }\end{array}$ & $\begin{array}{c}\text { Body Surface Area } \\
\left(\mathrm{m}^{2}\right)\end{array}$ & Fat $\%$ \\
\hline 1 & 1 & 11 & 27.2 & 139.1 & 1.05 & 12.5 \\
\hline 3 & 1 & 8 & 27.8 & 136.8 & 1.04 & 19.4 \\
\hline 4 & 1 & 9 & 39.9 & 153.1 & 1.32 & 13.5 \\
\hline 6 & 2 & 12 & 38.0 & 148.2 & 1.26 & 16.3 \\
\hline 7 & 2 & 8 & 25.4 & 128.0 & 0.96 & 15.7 \\
\hline 8 & 3 & 15 & 42.4 & 160.9 & 1.41 & 10.9 \\
\hline 9 & 3 & 11 & 37.5 & 153.1 & 1.29 & 16.9 \\
\hline 10 & 3 & 12 & 45.2 & 156.3 & 1.41 & 17.5 \\
\hline 12 & 3 & 11 & 44.5 & 153.3 & 1.38 & 22.8 \\
\hline 13 & 4 & 15 & 48.6 & 160.4 & 1.49 & 26.0 \\
\hline 14 & 5 & 16 & 59.6 & 165.8 & 1.66 & 24.1 \\
\hline Mean & & 11.3 & 38.2 & 153.1 & 1.31 & 16.6 \\
\hline $\mathrm{SD}$ & & 2.6 & 9.2 & 10.6 & 0.19 & 4.9 \\
\hline
\end{tabular}




\section{Statistical analysis}

The variables were analyzed by means of descriptive statistics and presented as mean \pm standard deviation. The change in body weight was analyzed using the Student's t-test for paired samples and perceptual scales were analyzed by the Friedman test. Correlations were performed using the Pearson test. The analyses were carried out using the program GraphPad InStat version 3.00 for Windows, GraphPad Software, San Diego California USA, and the level of significance adopted was 5\%.

\section{Results}

The results for hydration status and sweat response during the training session are presented individually in Table 2.

Figure 1 illustrates the coloration of the urine pre- and posttraining for each athlete. Twelve $(92.3 \%)$ athletes began the session hypohydrated (color between 3-7) and only one (7.69\%) athlete (ID 11) began training euhydrated (color 2). At the end of the training session, ten $(76.92 \%)$ of the girls showed significant

Table 2: Body weight variations, \% of hydration, water intake, sweat volume and sweat rate during one training session.

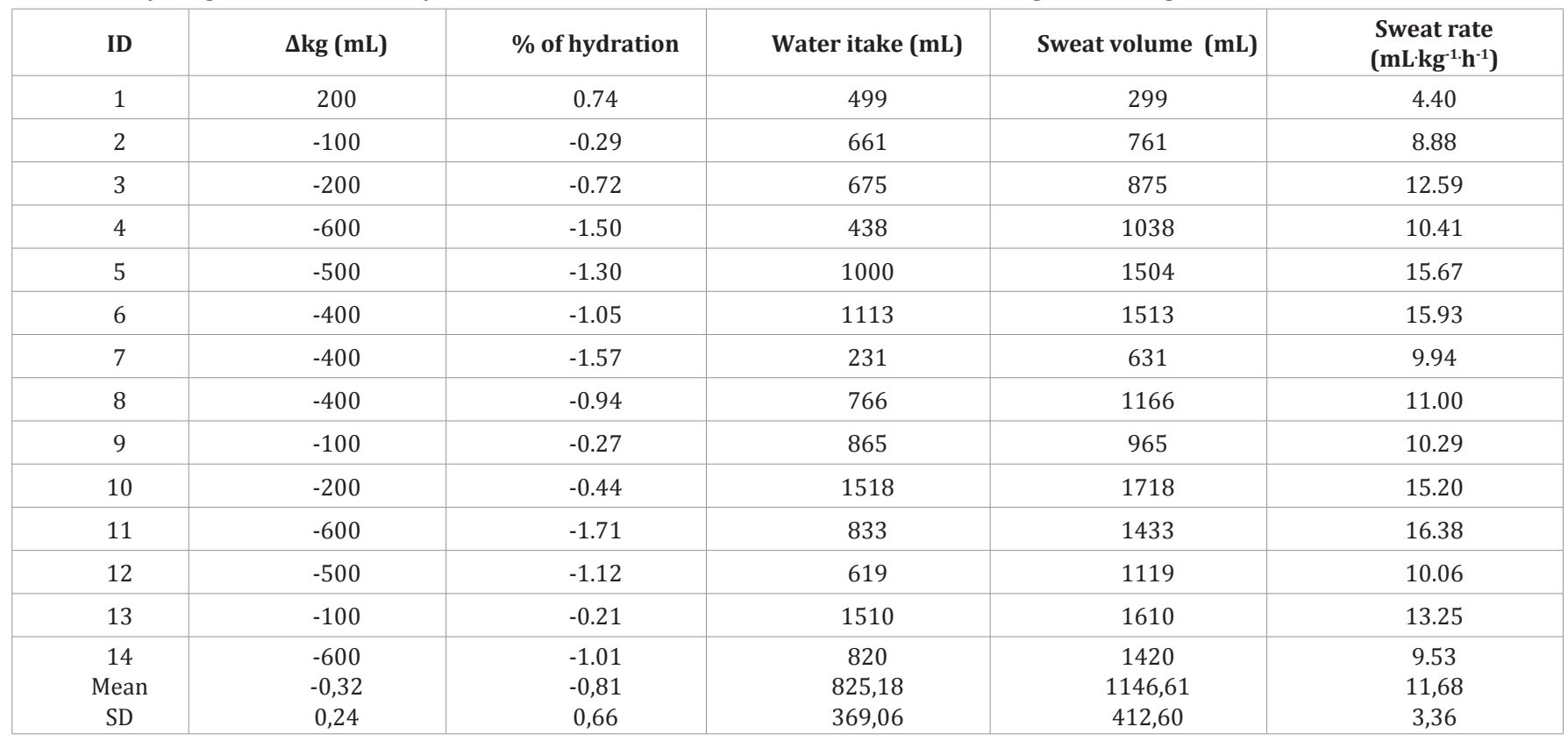

$\Delta \mathrm{kg}=$ Body weight variations

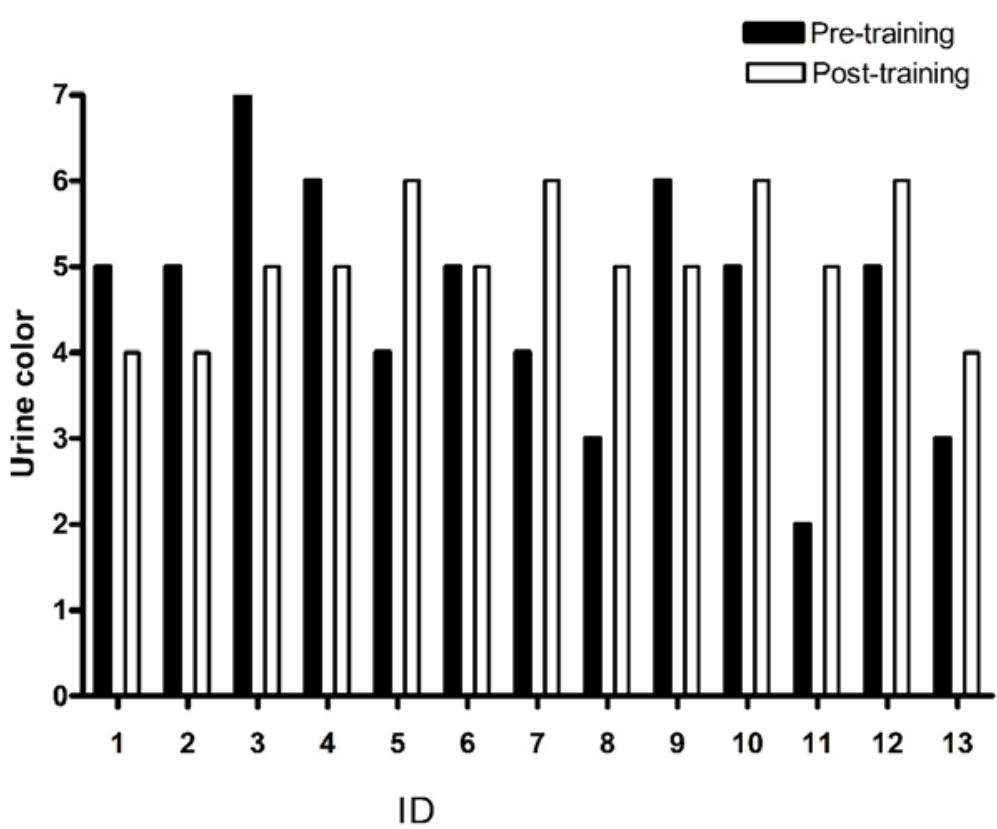

Figure 1: Coloration of the urine pre- and post-training for each athlete. 
hypohydration (color between 5-7), and the remaining three $(23.07 \%)$ were slightly hypohydrated (color 4$)$. The urine color of the athlete identified as ID 14 was not evaluated due to her menstrual cycle. The mean for pre- and post-training urine color did not present a difference (color 5 for both).

Thirteen girls had a reduction $(\mathrm{p}<0.001)$ in body weight $(-321.4 \pm 242.4 \mathrm{~g})$. The mean percentage of dehydration was $-0.81 \pm 0.67 \%$ and the greatest loss observed was $1.57 \%$. Water intake was $825.18 \pm 368.06 \mathrm{~mL}$. The mean for sweat volume and sweat rate were $1146.61 \pm 412.60 \mathrm{~mL}$ and $11.68 \pm 3.36 \mathrm{mLkg}^{-1} \mathrm{~h}^{-1}$, respectively. The data for sweating and hydration related to the variation in body weight, $\%$ hydration, fluid intake, sweat volume and rate of sweating of the young RG athletes during the training session are shown in Table 2.

No correlation was found between the state of hydration, according to urine color, prior to exercise and the volume of fluid ingested $(\mathrm{mL})(\mathrm{R}=-0.24, P=0.44)$. In addition, no correlation was found between the state of hydration prior to exercise, with respect to the urine color, and the $\%$ of dehydration $(\mathrm{R}=0.269$, $P=0.23$ ).

Table 3 shows the response rate for perceived exertion, thermal sensation, thermal comfort and irritability during the training session, measured every 30 min. No significant difference was observed in perceived exertion $(P=0.69)$ and irritability $(P=0.18)$ over the course of the workout. A nonsignificant increase in thermal sensation was observed $(P=0.08)$ and a reduction in thermal comfort $(P=0.08)$ during the 90th minute of the training session.

\section{Discussion}

The principle findings of this study were: (1) the athletes began the training session hypohydrated; (2) the percentage of body weight loss during the training session indicated that the RG athletes did not hydrate themselves adequately, despite having drinking water available ad libitum; (3) the prior hydration status was not related to the hypohydration seen post-training; and (4) the athletes presented an increased thermal sensation and decreased thermal comfort related to the training duration.

Despite the recommendation of hydrating with 375-500 $\mathrm{mL}$ of water 30 minutes prior to the beginning of the training session, 12 of the 13 athletes were classified as hypohydrated, with other studies having also observed this initial state [3-5]. The intake of 250-300 mL of water at the beginning of an activity and the further intake of around $150 \mathrm{~mL}$ every 20 minutes during the exercise is known to be among the recommendations for ensuring hydration [9], however, the athletes taking part in our study showed themselves to be commencing training already in a worrying state of hypohydration. The findings of this study reinforce the importance of encouraging hydration in the young RG athletes by prescribing fluid intake before, during and after training sessions, as they can fail to adequately recover from the dehydration suffered due to their daily training and competition schedules.

In the present study, one athlete hyperhydrated, six dehydrated less than $1 \%$, and seven dehydrated between $1-2 \%$, despite having water easily and readily available for drinking ad libitum. This result is in agreement with the study by Bar-Or, 0 [21], involving children aged between 10-12 years who presented hypohydration during prolonged exercise in the heat, even with fluids available. The American College of Sports Medicine [10] shows that hypohydration exceeding $1 \%$ is already detrimental to the performance and health of young athletes, and may cause a greater increase in body temperature, heart rate and fatigue, as well as a reduction in aerobic fitness $\left(\mathrm{VO}_{2 \max }\right)[20]$. Moreover, the study by Dougherty et al. [5] demonstrated that hypohydration in excess of $2 \%$ affects the performance related to the specific skills of basketball players.

Table 3: Rate of Perceived exertion (RPE), thermal sensation (TS), thermal comfort (TC) and irritability (IR) during the training session.

\begin{tabular}{|c|c|c|c|c|c|c|c|c|c|c|c|c|c|c|c|c|}
\hline \multirow[t]{2}{*}{ ID } & \multirow[b]{2}{*}{$30 "$} & \multicolumn{2}{|c|}{ RPE } & \multirow[b]{2}{*}{$120 "$} & \multirow[b]{2}{*}{$30 "$} & \multirow{2}{*}{$\begin{array}{c}\text { TS } \\
60 "\end{array}$} & \multirow[b]{2}{*}{$90 "$} & \multirow[b]{2}{*}{$120^{\prime \prime}$} & \multicolumn{2}{|c|}{ TC } & \multirow[b]{2}{*}{$90 "$} & \multirow[b]{2}{*}{$120 "$} & \multicolumn{3}{|c|}{ IR } & \multirow[b]{2}{*}{$120 "$} \\
\hline & & $60 "$ & $90 "$ & & & & & & $30 "$ & $60 "$ & & & $30 "$ & $60 "$ & 90" & \\
\hline 1 & 11 & 15 & 15 & 16 & 7 & 8 & 8 & 8 & 3 & 4 & 4 & 4 & 3 & 3 & 3 & 3 \\
\hline 2 & 15 & 15 & 13 & 15 & 8 & 8 & 8 & 8 & 3 & 3 & 3 & 3 & 3 & 1 & 3 & 3 \\
\hline 3 & 11 & 13 & 11 & 13 & 8 & 8 & 7 & 7 & 4 & 5 & 5 & 4 & 1 & 1 & 1 & 1 \\
\hline 4 & 17 & 17 & 17 & 17 & 5 & 5 & 8 & 8 & 3 & 2 & 5 & 5 & 2 & 3 & 3 & 1 \\
\hline 5 & 13 & 13 & 11 & 11 & 8 & 8 & 9 & 8 & 2 & 2 & 2 & 3 & 1 & 3 & 3 & 3 \\
\hline 6 & 11 & 11 & 11 & 11 & 7 & 8 & 8 & 8 & 5 & 3 & 3 & 4 & 2 & 2 & 2 & 2 \\
\hline 7 & 11 & 9 & 9 & 9 & 8 & 8 & 9 & 8 & 3 & 2 & 3 & 2 & 1 & 1 & 1 & 1 \\
\hline 8 & 9 & 9 & 15 & 17 & 9 & 8 & 7 & 9 & 2 & 2 & 5 & 5 & 2 & 2 & 2 & 2 \\
\hline 9 & 15 & 15 & 17 & 13 & 7 & 7 & 8 & 4 & 4 & 4 & 5 & 3 & 3 & 3 & 3 & 2 \\
\hline 10 & 9 & 7 & 9 & 11 & 5 & 5 & 5 & 7 & 1 & 2 & 2 & 3 & 1 & 1 & 1 & 1 \\
\hline 12 & 11 & 15 & 15 & 15 & 8 & 8 & 9 & 8 & 3 & 4 & 4 & 4 & 3 & 3 & 4 & 3 \\
\hline 13 & 11 & 9 & 9 & 9 & 8 & 8 & 9 & 7 & 3 & 2 & 4 & 2 & 1 & 1 & 3 & 1 \\
\hline 14 & 11 & 9 & 9 & 9 & 8 & 9 & 9 & 7 & 3 & 4 & 4 & 3 & 1 & 1 & 1 & 1 \\
\hline
\end{tabular}


The volume of water consumed by the athletes in the 150 minutes of training was on average $71 \%(825.18 \mathrm{~mL})$ of the volume of sweat produced (1146.61 mL). Rivera-Brown et al. [13] evaluated 12 young athletes ( $10.6 \pm 0.2$ years) in an environmental chamber, using a protocol of 180 minutes of cycling with an intensity of $60 \%$ of $\mathrm{VO}_{2 \max }$ in heat $\left(30.9 \pm 0.2^{\circ} \mathrm{C}\right)$; the voluntary water intake was $90 \%(950 \mathrm{~mL})$ of the sweat volume $(1050 \mathrm{~mL})$. In the present study, the athletes presented a greater percentage of hypohydration than in the study by Rivera-Brown et al. [13], however, sweating responses are related to individual factors (genetics, activity level, aerobic fitness), linked to the activity or sport (evaluation site, physical exercise intensity), as well as external conditions (temperature, relative humidity) [9].

In the present study, perceived exertion and thermal sensation remained constant during the training session, being as the mean reported perceived exertion related to the intensity of the training session was 13 , considered slightly tiring. The volume and intensity of the training session and the environmental conditions were similar for all the athletes. In regards to the thermal sensation of the athletes, the mean observed was 8 to 9 points, considered "warm to hot", and corresponding with the ambient temperature of the day. Thermal comfort reduced during training with a mean of 3 points, considered "just comfortable". The increased feeling of heat and reduced thermal comfort during training may be related to the reduction in performance and/or motivation of the athletes [19]. Also, the irritability of the athletes was classified as low and it is believed that this result is an outcome of adaptation to the training and environmental conditions.

\section{Conclusion}

Training sessions for RG are intense and continuous and we stress the importance of encouraging fluid intake prior to and during these workouts, especially when conducted in the heat, which may compromise performance and health. Moreover, we believe that further research involving RG athletes should be carried out, verifying the impact of hypohydration on the performance of specific skills and the use of other forms of drink for fluid replacement.

\section{References}

1. Bozanic A, Miletic D (2011) Differences between the sexes in technical mastery of rhythmic gymnastics. J Sports Sci 29(4): 337-343.

2. S Gibson, P Gunn, RJ Maughan (2012) Hydration, water intake and beverage consumption habits among adults. Nutrition Bulletin 37(3): 182-192.

3. Rivera-Brown AM, De Félix-Dávila RA (2012) Hydration status in adolescent judo athletes before and after training in the heat. Int J of Sports Physiol Perform 7(1): 39-46.

4. Claudia A Perrone, Paulo L Sehl, Jocelito B Martins, Flavia Meyer (2011) Hydration status and sweating responses of boys playing soccer and futsal. Med Sport 15(4): 188-193.

5. Dougherty KA, Baker LB, Chow M, Kenney WL (2006) Two percent dehydration impairs and six percent carbohydrate drink improves boys basketball skills. Med Sci Sports Exerc 38(9): 1650-58.

6. Wilk B, Aragon-Vargas IF, Bar-Or O (2001) Involuntary dehydration in children and adolescents following triathlon race in a hot climate. Medicine and Science in Sports and Exercise 33: 137.

7. Bergeron MF, Waller JL, Marinik EL (2006) Voluntary fluid intake and core temperature responses in adolescent tennis players: sports beverage versus water. Br J Sports Med 40(5): 406-410.

8. Bergeron MF, Laird MD, Marinik EL, Brenner JS, Waller JL (2009) Repeated-bout exercise in the heat in young athletes: physiological strain and perceptual responses. J Appl Physiol 106(2): 476-485.

9. Meyer F, Volterman KA, Timmons BW, Wilk B (2012) Fluid balance and de- hydration in the young athlete: assessment considerations and effects on health and performance. American Journal of Lifestyle Medicine 6(6): 489-501.

10. Sawka MN, Burke LM, Eichner ER, Maughan RJ, Montain SJ, et al. (2007) American College of sports medicine position stand. Exercise and fluid replacement. Med Sci Sports Exerc 39(2): 377-390.

11. Bar-Or O (1989) Perspectives in Exercise and Sports Medicine: Youth and, Exercise and Sports. In: Gisolfi CV \& Lamb DR (Eds.), Temperature regulation during exercise in children and adolescents. Benchmark Press, Indianápolis, pp. 335-367.

12. Rivera-Brown AM, Rowland TW, Ramírez-Marrero FA, Santacana G, Vann A (2006) Exercise Tolerance in Hot and Humid Climate in HeatAcclimatized Girls and Woman. Int J of Sports Med 27(12): 943-950.

13. Rivera-Brown AM, Ramírez-Marrero FA, Wilk B, Bar-Or 0 (2008) Voluntary drinking and hydration in trained, heat-acclimatized girls in a hot and humid climate. Eur J Appl Physiol 103(1): 109-116.

14. Gabriela Tomedi Leites, Paulo Lague Sehl, Giovani dos Santos Cunha, Adriano Detoni Filho, Flavia Meyer (2013). Responses of obese and lean girls exercising under heat and thermoneutral conditions. The Journal of Pediatrics 162(5): 1054-1060.

15. DELAFIELD Du BOIS, EUGENE F Du BOIS (1916) Clinical calorimetry: a formula to estimate the approximate surface area if height and weight be known. Arch Intern Med (Chic) 17(6_2): 863-71.

16. Slaughter MH, Lohman TG, Boileau RA, Horswill CA, Stillman RJ, et al. (1988) Skinfold equations for estimation of body fatness in children and youth. Hum Biol 60(5): 709-723.

17. Armstrong LE, Maresh CM, Castellani JW, Bergeron MF, Kenefick RW, et al. (1994) Urinary indices of hydration status. Int J of Sport Nutr 4(3): 265-279.

18. Borg G (1970) Perceived exertion as an indicator of somatic stress. Scand J Rehabil Med 2(2): 92-98.

19. Edward Arens, Hui Zhang, Charlie Huizenga (2006) Partial - and wholebody thermal sensation and comfort - Part I: Uniform environmental conditions. Journal of Thermal Biology 31(1-2): 53-59.

20.Greenleaf JE (1992) Problem: thirst, drinking behavior, and involuntary dehydration. Med Sci Sports Exerc 24(6): 645-656.

21. Bar-Or O (1980) Climate and the exercising child - a review. International Journal of Sports Medicine. 1: 53-65. 